\title{
Püskürtmeli Kurutucu ile Nane (Mentha piperita ve Mentha spicata) Esansiyel Yağı Mikroenkapsülasyonu
}

\author{
Bülent BAŞYiĞiT ${ }^{1 *}$, Mustafa ÇAM² \\ ${ }^{1}$ Harran Üniversitesi Ziraat Fakültesi Gıda Mühendisliği Bölümü, Şanlıurfa \\ ${ }^{2}$ Erciyes Üniversitesi Mühendislik Fakültesi Gıda Mühendisliği Bölümü, Kayseri \\ *Sorumlu yazar: bulentbasyigit@harran.edu.tr
}

Öz

Bu çalışmada yaygın kullanım alanlarına sahip olan nane (Mentha piperita ve Mentha spicata) esansiyel yağlarının mikroenkapsülasyon olanakları araştııılmıs ve mikroenkapsülasyon için gerekli olan kaplama materyallerinin oranını belirlemede optimizasyon işlemi gerçekleştirilmiştir. Mentha spicata esansiyel yağı deneme tasarımı için 4 adet cevap (verim, etkinlik, esansiyel yağ hapsetme etkinliği ve Hausner oranı) sistemin optimize edilmesinde kullanılmıştır. Optimizasyon işlemi sonuçlarına göre maltodekstrinarap zamkı kombinasyonunun (\%62-38) ve \%100 arap zamkı kullanımının nane (Mentha piperita ve Mentha spicata) esansiyel yağları mikroenkapsüle etmek için optimum noktalar olduğu belirlenmiştir. Yapılan analizler sonucunda duvar materyalinin oranına ve esansiyel yağın elde edildiği nanenin türüne göre verim, etkinlik, esansiyel yağ hapsetme etkinliği, Hausner oranı, Carr indeks, ıslanabilirlik (sn) ve su aktivitesi değerlerinin değişkenlik gösterdiği görülmüştür. Bu verilerin ışığı altında maliyeti günden güne artan arap zamkı kaplama maddesinin kullanımını azaltıcı olarak maltodekstrin-arap zamkı kombinasyonları için optimum noktalar belirlenmiştir.

Anahtar Kelimeler: Mikroenkapsülasyon, Püskürtmeli kurutucu, Arap zamkı, Maltodekstrin, Esansiyel yağ

\section{Microencapsulation of Peppermint (Mentha piperita and Mentha Spicata) Essential Oil by Spray-Dryer}

\begin{abstract}
Absract
Microencapsulation possibilities of mint essential oils used commonly at different industries were investigated and optimized. Four parameters were evaluated in optimization that were yield, efficiency, essential oil trapping efficiency and Hausner ratio. Optimum points were found as combination of maltodextrin-gum arabic (62-38\%) and $100 \%$ gam arabic to microencapsulate esential oils. It was found that efficiency, effectiveness, efficiency of essential fatty entrapment, Hausner ratio, Carr index, wettability $(\mathrm{sec}$ ) changed by depending on wall material ratio and mint type. The results suggested that combination of maltodextrin-gum arabic can be alternative instead of using gum arabic alone.
\end{abstract}

Keywords: Microencapsulation, Spray-dryer, Gum arabic, Maltodextrin, Essential oils

Giriş

Esansiyel yağların aroma terapide kullanımı artış göstermektedir. Nanenin en çok üzerinde durulan ve kullanım alanı açısından en yaygın kısmı esansiyel yağ fraksiyonudur (Ciobanu ve ark., 2013). Nane esansiyel yağı antiseptik ve bölgesel anestezik özelliklere sahip olup ağrı giderici, kan akışını hızlandırıcı etkiler sergilemektedir. Nane ve nane yağı safra sıvılarının miktarını artırmakta ve bu ürünler hazımsızlık gibi problemleri önlemede 
kullanılmaktadır. (Mimica-Dukic ve ark., 2003). Yapılan bir çalışmada nanenin esansiyel yağ fraksiyonu \%0,5-1 arasında olduğu belirtilmiştir (Raja ve ark., 2012). Mentha piperita esansiyel yağ fraksiyonunda "mentol", "menton" ve "metil asetat" hakim bileşikleridir (Ciobanu ve ark., 2013). Yapılan bir çalışmada Mentha piperita esansiyel yağının hakim bileşenin \%39,6 oranında bulunan mentol olduğu bunu metil asetat $(\% 10,4)$ ve menton $(\% 8,9)$ bileşiklerinin takip ettiği ve toplam tanımlanan bileşen sayısının 30 olduğu belirlenmiştir (Mimica-Dukic ve ark., 2003). Bir diğer çalışmada mentolün nanede $\% 27,5-42,3$ ve menton bileşiğinin ise $\% 18,4-27,9$ düzeyinde bulunduğu belirlenmiştir (İ̧scan ve ark., 2002).

Mentha spicata da ise büyük oksijenli monoterpenlerden carvone (Şekil 1), cis carveol ve limonen esansiyel yağın $\% 80$ 'inden oluşturmaktadır (Aggarwal et al., 2002; Younis and Beshir, 2004; Hussain et al., 2010; Şarer et al., 2011). Fakat bu esansiyel yağın ana bileşeninin carvone olduğu saptanmıştır (Lucchesi et al., 2004; Oliveira et al., 2012). Bu bileşik ekonomik olup tatlandırıcı, koku verici, inhibitör olarak ve tıp alanında kullanılmasının yanı sıra antimikrobiyal etkiye de sahiptir (Decarvalho and Dafonseca, 2006). Ayrica taze, kurutulmuş Mentha spicata ve Mentha spicata esansiyel yağı gıda, kozmetik, şekerleme, sakız, diş macunu ve ilaç endüstrisinde yaygın olarak kullanılmaktadır (Lawrence, 2006).

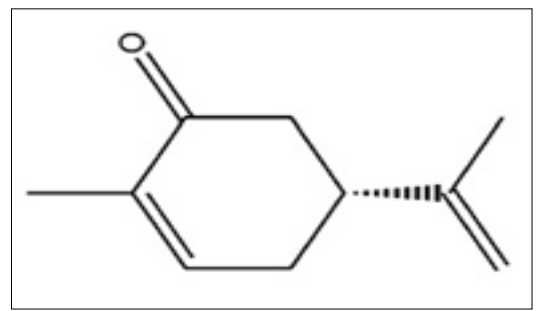

Şekil 1. Carvone bileşiği yapısı Figure 1. Structure of Carvone
Nane esansiyel yağının seçilmiş bazı mikroorganizmalara (Esherichia coli, Staphylococcus aureus, Shigella sonei, Micrococcus flavus, Salmonella typhimurium, Trichophyton tonsurans, Candida albicans) karşı antimikrobiyal etkisi olduğu belirlenmiştir (İşcan ve ark., 2002; MimicaDukic ve ark., 2003; Karagözlü ve ark., 2011).

Koku verici uçucu bileşenler ile esansiyel yağların stabilitesi mikroenkapsülasyon tekniği ile önemli derecede arttırımaktadır. Gıda sanayinde mikroenkapsülasyon uçucu bileşiklerin buharlaşması ve oksidasyonunu önlemede kullanılabilmek ayrıca yeni işlenmiş gıdaların üretilmesine de imkan sağlamaktadır. Diğer avantajlar ise mikrokapsül haldeki ürünlerin katı gıdalara kolayca uygulanabilmesi, enkapsüle edilmiş aktif maddenin zamanla kontrollü salınımı, gelişmiş/düzeltilmiş tat sağlaması ve ürünün raf ömrünün uzatılmasıdır (Wojtowicz ve ark., 2010).

Mikroenkapsülasyonda kaplama maddesi olarak kullanılabilecek çok fazla bileşen mevcut ise de bunları karbonhidrat ve protein başlığı altında toplamak mümkündür. Aroma ve yağların mikroenkapsülasyonunda maltodekstrin, hidrolize nişasta, modifiye nişasta, siklodekstrin ve gamlar gibi karbonhidratlar kullanılmaktadır. Proteinlerden ise süt proteinleri, peynir altı suyu proteinleri ve soya proteinleri gibi kaplama maddeleri yaygın olarak kullanılagelmiştir. Belirtilen kaplama maddelerinden hiçbiri tek başına optimum fayda sağlamaz bunun yerine değişik grup kaplama maddelerinin kombinasyonu tercih edilmesi uygun görülmektedir. Yağların ve aroma maddelerinin mikroenkapsülasyonunda kaplama materyalleri arasında arap zamkı ön plana çıkmaktadır. Özellikle uçucu nitelikte olan aroma maddeleri söz konusu olduğu zaman 
arap zamkının daha efektif sonuçlar verdiği belirlenmiştir. Arap zamkının önemli bir diğer özelliği de su fazında apolar bileşikler için emülsiyon oluşturma kapasitesinin yüksek olmasıdır (Jafari ve ark., 2008). Suda çözünmez özellikte esansiyel yağlar, lipitler gibi bileşiklerin mikroenkapsülasyon işlemi için ilk aşama bu bileşenlerin suda emülsiyonunun sağlanmasıdır. Bu işlem bir emülsifiyer ajan veya emülsifiye etme özelliği olan bir kaplama maddesi ile gerçekleştirilebilir.

Mikroenkapsülasyon işlemi püskürtmeli kurutma, dondurarak kurutma, akışkan yatak kaplama gibi birçok tekniklerle gerçekleştirilebilmektedir. Bu yöntemler arasında püskürtmeli kurutucu en çok tercih edilen yöntemdir. Gıda endüstrisinde yaygın olarak bulunan bu ekipman ile geniş çapta üretimler yapılması mümkündür (Eichler, 2003). Püskürtmeli kurutucu Kurutma masrafları dondurarak kurutma işlemine göre 30-50 kat daha düşüktür (Moreau ve Rosenberg, 1996). Püskürtmeli kurutucuda gerçekleştirilen mikroenkapsülasyon işlemi sonucunda kaplama maddesinin duyarlı gıda bileşenini tutması, çevresel faktörlerden izole etmesi ve oksidasyona karşı koruması sağlanmaktadır (Desorby ve ark., 1997; Cai ve Corke, 2000). Aroma maddelerinin kaplanmasında en çok tercih edilen yöntem olmuştur. Aroma çalışmalarının \%85' lik bölümünde bu teknik kullanılmaktadır. Bu işlem esnasında çözücüyü buharlaştırmak amacıyla kullanılan sıcak hava 150-200 ㄷ dolaylarında olmasına rağmen hem bu sıcaklık ile aktif bileşenin temas süresinin kısa olmakta (1-5 saniye) hem de elde edilen ürünün sıcaklığı 50-80 ㄷ civarında olmakta bu da bileşenlerin termal degradasyonunu sınırlamaktadır (Gharsallaoui ve ark., 2007).

$\mathrm{Bu}$ çalışmanın amacı nane (Mentha spicata ve Menthta piperita) esansiyel yağlarını, farklı oranlarda maltodekstrin ve arap zamkı kombinasyonu kullanarak püskürtmeli kurutucu ile mikroenkapsüle halde, suda çözünebilir formda (instant) tozlar üretmektir. Ayrıca bu tozlarda mikroenkasülasyon verimi ve etkinliği, esansiyel yă̆ hapsetme etkinliği, toz örneklerde kitle ve sıkıştırılmış kitle yoğunluğu (Hausner oranı, Carr indeks), ıslanabilirlik (sn) ve su aktivitesi analizleri yapılmıştır.

\section{Materyal ve Metot}

Mentha spicata esansiyel yağı su buharı distilasyonu ile elde edilmiştir. Mentha piperita esansiyel yağı ise piyasadan (Arifoğlu Baharat) $100 \mathrm{~mL}$ 'lik amabalajlarda temin edilmiştir. Reaktifler ve çözücüler analitik saflıkta olup Merck ve Sigma firmalarından temin edilmiştir.

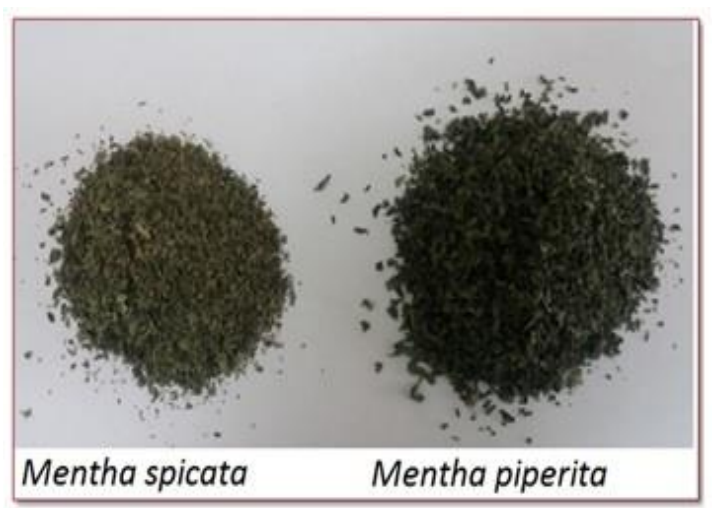

Şekil 1. Çalışmada kullanılan nane türleri

Figure 1. Mint species used in the study

\section{Esansiyel yağ ekstraksiyonu}

Kullanılan nane yağlarından Mentha spicata esansiyel yağı kurutulmuş haldeki bitkinin kendisinden su buharı ile distile edilmiştir. 100 gram örnek üzerine $250 \mathrm{~mL}$ saf su eklenerek 2 saat boyunca distile edilen örnekten alınan esansiyel yağ $\mathrm{Na}_{2} \mathrm{SO}_{4}$ ile kurutulmuştur. Mentha piperita esansiyel yağı ise piyasadan (Arifoğlu Baharat) temin 
edilmiştir. Herhangi bir şekilde safsızlıklar içermesi intimali göz önüne alınarak bu örnek 2 saat yukarıda anlatıldığı gibi buhar distilasyonuna tabi tutulmuş ve distile olarak alınan esansiyel yağ $\mathrm{Na}_{2} \mathrm{SO}_{4}$ ile kurutulmuştur. Örnekler $+4{ }^{\circ} \mathrm{C}^{\prime} \mathrm{de}$ depolanmıştır.

\section{Esansiyel yağ mikroenkapsülasyonu}

2 adet nane yağı (Mentha spicata ve Mentha piperita) örneğinden Mentha spicata yağı model olarak seçilmiş ve arap zamkı ile maltodekstrin (DE 13-17) kombinasyonları Simplex Lattice deneme tasarımına göre oluşturulmuştur. Denemeler boyunca esansiyel yağ miktarının kaplama maddesi miktarına oranı (1:6) olarak tutulmuştur. Değişen ise bu kaplama maddelerinin oranları olmuştur (Çizelge 1).

Buna göre mikroenkapsülasyon işlemi için aşağıdaki belirtilen işlemler uygulanmıştır. Toplam 24 gram olacak şekilde kaplama maddeleri $100 \mathrm{~mL}$ su içerisinde çözündürülerek ultraturrax'da (IKA T18)
20000 devirde 5 dakika boyunca karıştırılarak kaplama maddelerinin hidrate olması için 8 saat süreyle bekletilmiştir. Esansiyel yağ: kaplama maddesi oranı 1:6 olacak şekilde yukarıdaki solüsyona 4 gram nane esansiyel yağı ilave edilerek tekrar Ultraturrax'da homojenize edilmiştir. Bu çözelti püskürtmeli kurutucuya (BÜCHI B-290) beslenerek kurutulmuş ve elde edilen mikroenkapsüle nane esansiyel yağları elde edilmiştir. Elde edilen mikrokapsüller analiz edilene kadar $4^{\circ} \mathrm{C}$ 'de karanlıkta şişeler içerisinde saklanmıştır. Püskürtmeli kurutucu çözelti besleme hızı $8 \mathrm{~mL} /$ dakika, aspiratör çalışma hızı \%100, kuru hava besleme hızı ise 600 L/saat olarak ayarlanıp önce saf su beslemeye başlanmış ve sistem sıcaklık açısından dengeye geldikten sonra hazırlanan çözelti beslenmiştir. Püskürtmeli kurutucu giriş sıcaklığı $140{ }^{\circ} \mathrm{C}$ olarak sabit tutulmuş ve çıkış sıcaklıklarının aldığı değerler ve verimler daha sonradan hesaplanmıştır.

Çizelge 1. Nane esansiyel yağı için kaplama maddesi oranlarına ait Simplex lattice dizayn

Table 1. Simplex lattice design of the coating material rate for peppermint essential oil

\begin{tabular}{|c|c|}
\hline Arap zamkı (Gam arabic) (\%) & Maltodekstrin (Maltodextrin) (\%) \\
\hline 100 & 50 \\
\hline 50 & 75 \\
\hline 25 & 100 \\
\hline 0 & 100 \\
\hline 0 & 50 \\
\hline 50 & 25 \\
\hline 75 & 0 \\
\hline 100 &
\end{tabular}

Fiziksel ve Fizikokimyasal Analiz Metotları

\section{Su aktivitesi}

Mikroenkapsüle edilmiş örneklerin su aktiveleri literatüre not edilmiş bir metot ile Aqualab model bir su aktivitesi cihazı ile belirlenmiştir (Aqualab Model Seri 3TE, USA) (Tatar ve ark., 2014).

\section{Islanabilirlik}

Islatabilirlik değerinin belirlenmesi amacıyla 1 gram mikroenkapsüle nane yağının su $\left(100 \mathrm{~mL}, 20{ }^{\circ} \mathrm{C}\right)$ yüzeyinden kaybolması süresi hesaplanmıştır (Turchiuli ve ark., 2005).

Kitle yoğunluğu (bulk density) ve sıkıştırılmış kitle yoğunluğu (tapped density) 
Mikroenkapsüle edilmiş örneklerin kitle yoğunluğu ve sıkıştırılmış kitle yoğunluğu literatürde not edilen bir metodun kısmı modifikasyonuna göre yapılmıştır (Tatar ve ark., 2014). Buna göre mikroenkapsüle örneklerden 3 gram alınarak $20 \mathrm{~mL}$ mezür içerisine belirli bir yükseklikten aktarılmıştır. Örneklerin kütlesi kapladığı hacme oranlanarak kitle yoğunluğu değerleri belirlenmiştir. Ardından sıkıştırılmış kitle yoğunluğunu hesaplamak amacıyla mikroenkapsüle örneklerin bulunduğu mezürler düz bir zemine 200 defa elle vurularak işlem gerçekleştirilmiş ve kütlenin sıkıştırılmış hacme oranı ile sıkıştırılmış kitle yoğunluğu değerleri belirlenmiştir.

\section{Hausner oranı ve Carr indeks}

Mikroenkapsüle edilmiş örneklerin Hausner oranı sıkıştırılmış kitle yoğunluğu değerinin kitle yoğunluğuna oranlanması ile belirlenmiştir. Carr indeks ise formül 1'e göre belirlenmiştir. Carr Index ve Hausner Oranına göre akışkanlık değerleri (Turchiuli ve ark., 2005) toz haldeki ürünlerin akışkanlık durumları hakkında bilgi vermektedir (Çizelge 2).

Carr indeks $=\left(\frac{\text { Slkıştırılmış kitle yoğunluğu-Kitle yoğunluğu }}{\text { Sıkıştırılmış Kitle yoğunluğu }}\right) * 100$

Çizelge 2. Carr indeks, Hausner oranı ve akışkanlık ilişkisi

Table 2. Relationship of Carr index, Hausner ratio and flowability

\begin{tabular}{|c|c|c|}
\hline Carr Indeks (Carr Index) & Akışkanlık (Fluidity) & Hausner Oranı (Hausner Ratio) \\
\hline$\leq 10$ & Mükemmel (Excellent) & $1,00-1,11$ \\
\hline $11-15$ & İyi (Good) & $1,12-1,18$ \\
\hline $16-20$ & Orta (Middle) & $1,19-1,25$ \\
\hline $21-25$ & Geçerli (Valid) & $1,26-1,34$ \\
\hline $26-31$ & Zayıf (Weak) & $1,35-1,45$ \\
\hline $32-37$ & Çok zayıf (Too weak) & $1,46-1,59$ \\
\hline $38 \geq$ & Çok kötü (Very bad) & $1,60 \geq$ \\
\hline
\end{tabular}

Nane (M.sipicata ve M.piperita) esansiyel yağı mikroenkapsülasyonu işleminin verimi

Nane esansiyel yağları maltodekstrin ve arap zamkı (\%38-62) kombinasyonu ile mikroenkapsüle edildikten sonra elde edilen mikrokapsül miktarı ve buna girdi oluşturan bileşenlerin kütleleri üzerinden formül 2'ye göre hesaplanmıştır (QuispeCondori ve ark, 2011; Çam ve ark, 2014).

$\operatorname{Verim}(\%)=\frac{\text { Püskürtmeli kurutucudan elde edilen mikrokapsüllerin kütlesi }}{\text { Püskürtmeli kurutucuya beslenen girdilerin kütlesi (kuru madde üzerinden) }} * 100$

Nane esansiyel yağı mikroenkapsülasyonu işleminin etkinliği

Mikroenkapsüle edilmiş nane yağı örneklerinin yüzey yağ miktarları Gaz kromotografisi-Alev iyonizasyon dedektörü (GC-FID) (Agilent-6890N) ile belirlenmiştir.
Bu amaçla 0,5 gram örnek $10 \mathrm{~mL}$ pentanda çözündürülüp filtre edildikten sonra $1 \mu \mathrm{L}^{\prime}$ lik kısmı gaz kromatografisine enjekte edilmiştir. Yüzey yağ miktarını belirlemek amacıyla oluşturulan kalibrasyon grafiği şekil 2 ve 3'te verilmiştir. Analiz için TR5- 
MS kolon $(60 \mathrm{~m} \times 0.25 \mathrm{~mm}, 0.25 \mu \mathrm{m})$ kullanılmıştır. Çalışma koşulları: dedektör ve enjeksiyon sıcaklıkları sırasıyla 280 ve $260{ }^{\circ} \mathrm{C}$ olup akış hızı $1 \mathrm{~mL} /$ dak'dır. Taşıyıcı gaz olarak helyum kullanılmıştır.

Belirtilen kromatografik koşullarda 2 tip nane için esansiyel yağlar ile kalibrasyon grafikleri oluşturulmuştur (Şekil 2,3). Kalibrasyon grafikleri yardımıyla ürünlerin yüzeyinde kalan yağ miktarları belirlenmiştir.
Mikroenkapsüle haldeki tozların toplam esansiyel yağ miktarını belirlemek için ise enkapsüle edilen örneklerden 7,5 gram alınarak 2 saat su buharı distilasyonuna tabi tutulmuştur. Distilasyonla elde edilen esansiyel yağ miktarı da gravimetrik olarak belirlenmiştir. Belirlenen esansiyel yağ miktarından yararlanılarak enkapsülasyon etkinliği ve hapsetme etkinliği sırasıyla formül 3 ve 4'e göre hesaplanmıştır (Sarkar et al, 2013).

$\operatorname{Etkinlik}(\%)=\left(\frac{\text { Mikrokapsülde deneysel belirlenen toplam esansiyel yă̆ }\left(\frac{g}{g \text { mikrokapsül }}\right)}{\text { Mikrokapsüldeki teorik esansiyel yă̆ }\left(\frac{g}{g \text { mikrokapsül }}\right)}\right) * 100$

Hapsetme Etkinliğ $i(\%)=\left(\frac{\text { Mikrokapsülün toplam esansiyel yağ l-Mikrokapsülün Yüzey esansiyel yağl }}{\text { Mikrokapsülün toplam esansiyel yağ } l}\right) * 100$

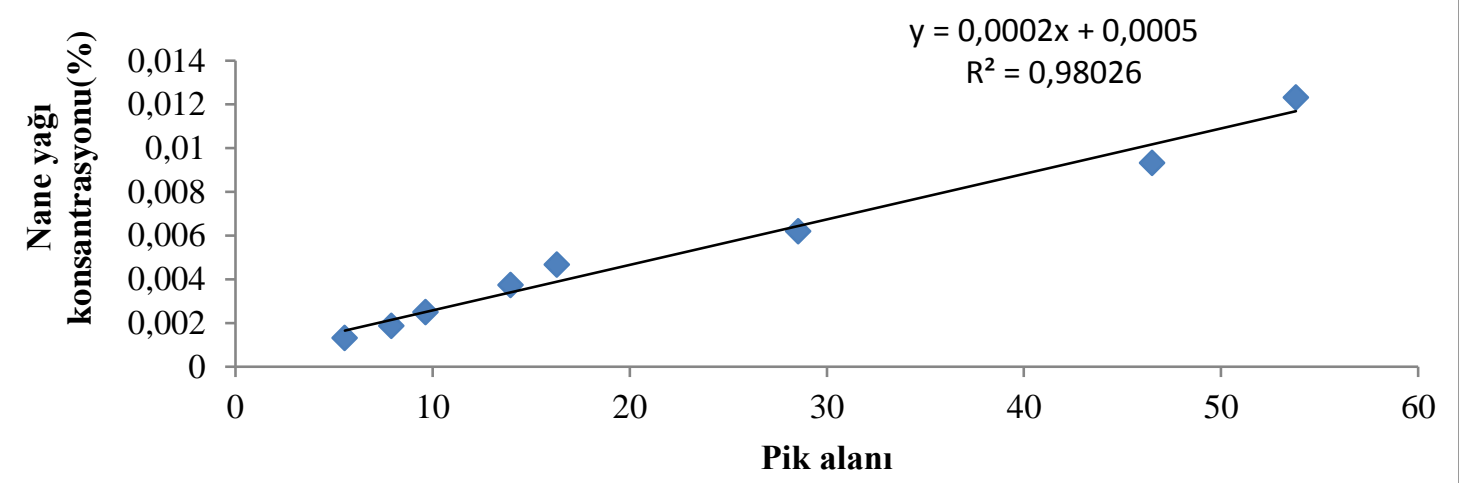

Şekil 2. Mentha piperita örnekleri yüzey esansiyel yağ hesaplanması için kalibrasyon grafiği Figure 2. The calibration graph to calculate the surface essential oil of Mentha piperita samples

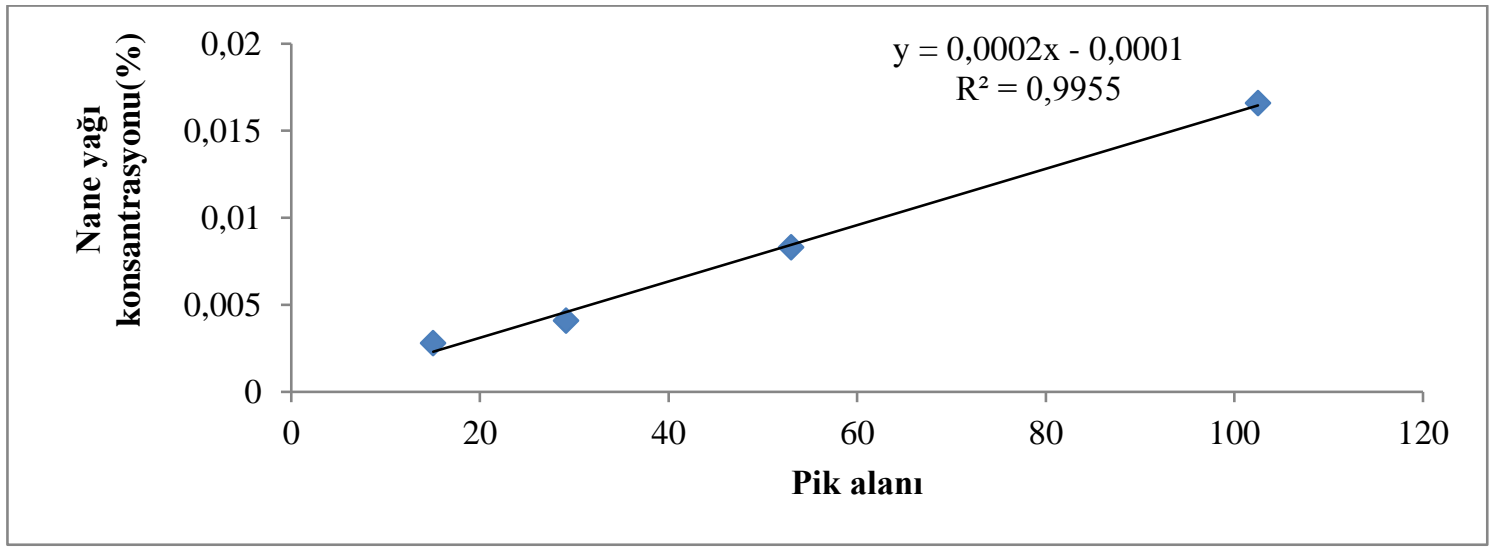

Şekil 3. Mentha spicata örnekleri yüzey esansiyel yağ hesaplanması için kalibrasyon grafiği Figure 3. The calibration graph to calculate the surface essential oil of Mentha spicata samples 
Istatistiksel Analiz Metotları

Deneme tasarımları Design Expert 7.0 paket programı ile oluşturulmuş ve alınan veriler bu program ile yorumlanmıştır. Elde edilen tasarımların istatistiksel olarak analizleri SPSS 10.0.1 (SPSS Inc., Chicago, USA) paket programı kullanılarak belirlenmiştir.

\section{Araştırma Bulguları ve Tartışma}

Esansiyel yağ mikroenkapsülasyonu için optimum noktaların belirlenmesi

Mentha spicata esansiyel yağının arap zamkı ve maltodekstrin kombinasyonu ile mikroenkapsüle edilerek mikrokapsüllerin özellikleri incelenmiştir (Çizelge 3).

Deneme tasarımı için 4 adet cevap (Verim, etkinlik, esansiyel yağ hapsetme etkinliği ve Hausner oranı) sistemin optimize edilmesinde kullanılmıştır.. Paket program tarafından 4 adet cevap için oluşturulan bütün modeller istatistiksel anlamda önemli bulunmuştur. Alınan bu sonuçlara göre yapılan optimizasyon işlemi ile mikroenkapsülasyon için maltodekstrin arap zamkı kombinasyonunun (\%62-38) ve \%100 arap zamkı kullanımının optimum noktalar olduğu belirlenmiştir. Her iki noktanın arzu edilebilirlik (desirability) değerleri Design Expert programı ile sırasıyla 0.666 ve 0.729 olarak belirlenmiştir. Bu optimum noktalarda $\mathrm{M}$. spicata esansiyel yağı ve $M$. piperita esansiyel yağı mikroenkapsüle edilerek analizleri yapılmıştır (Çizelge 4).

Mikroenkaspsülasyon işleminin verimi mikroenkapsüle edilen örneğin türüne, kullanılan duvar materyalinin çeşidi ve solüsyondaki oranına göre değiştiği belirlenmiştir. Mentha spicata örneklerinde mikroenkapsülasyon verimi Mentha piperita türüne göre daha yüksek olduğu ve solüsyondaki arap zamkı miktarı arttıkça mikroenkapsülasyon veriminin azaldığı saptanmıştır (Çizelge 4). Bu durum, arap zamkının solüsyonun viskozitesini arttırdığı dolayısıyla püskürtmeli kurutucu çeperlerine daha fazla örnek yapışmasına ve püskürtmeli kurutucu pompasının çalışma verimini olumsuz etkilemesine neden olduğundan kaynaklandığı tahmin edilmektedir. Tan ve ark. (2005) tarafından farklı yağlar kullanarak yapmış oldukları mikroenkapsülasyon işleminde benzer sonuçlara ulaşmışlardır.

Mikroenkapsülasyon işleminin yeteri düzeyde gerçekleşip gerçekleşmediğini mikroenkapsülasyon etkinliği ve esansiyel yağ hapsetme etkinliği temsil eder. Bu iki değer ne kadar yüksek olursa o kadar kaliteli bir mikroenkapsülasyon işlemi gerçekleşmiş demektir. En yüksek mikroenkapsülasyon etkinliği sadece arap zamkının duvar materyali olarak kullanıldığı solüsyonda bulunmuştur (Çizelge 4). Çünkü arap zamkı doğal bir polimer olup iyi bir film oluşturma özelliğine sahiptir (Bertolini ve ark., 2001). Benzer sonuçlara Tan ve ark. (2005) tarafından balık yağı mikroenkapsülasyonunda \%92, Sarkar ve ark. (2013) tarafından nane yağı mikroenkapsülasyonunda duvar materyali olarak arap zamkı kullanarak \%80.66 şeklinde bulmuştur. Yüzey yağ oranı mikroenkapsüle edilmiş tozların raf ömrü için en önemli parametrelerden biridir. Mikroenkapsül tozlar üzerindeki yüzey yağlar okside olduklarında istenmeyen kokulara sebebiyet verebilir. Dolayısıyla esansiyel yağ hapsetme etkinliği doğrudan yüzey yağın göstergesi olarak gösterilebilir (Sarkar ve ark., 2013). Arap zamkı ve maltodekstrin kombinasyonunun en yüksek esansiyel yağ hapsetme etkinliğine sahip olduğu saptanmıştır (Çizelge 4). Bu sonuç, Sarkar ve ark. (2013) tarafindan duvar 
materyali olarak arap zamkının kullanıldığı nane yağı mikroenkapsülasyonunda bulmuş olduğu \%86.26 ve Quispe-Condori ve ark. (2011) keten tohum yağı mikroenkapsülasyonunda ulaşmış oldukları değer benzerlik göstermiştir.

Çizelge 3. Mentha spicata esansiyel yağ mikroenkapsülasyonu için "Simplex-lattice" deneme tasarımı sonuçları

Table 3. Simplex-lattice" trial design results for microencapsulation of Mentha spicata essential

\begin{tabular}{|c|c|c|c|c|c|c|}
\hline \multirow{2}{*}{$\begin{array}{l}\text { Deneme } \\
\text { sırası } \\
\text { (Run) }\end{array}$} & \multicolumn{2}{|c|}{$\begin{array}{l}\text { Kaplama maddeleri } \\
\text { Coating materials }\end{array}$} & \multirow{2}{*}{$\begin{array}{c}\text { Verim } \\
\text { Yield } \\
(\%)\end{array}$} & \multirow{2}{*}{$\begin{array}{c}\text { Etkinlik (\%) } \\
\text { Encapsulation } \\
\text { efficiency } \\
(\%)\end{array}$} & \multirow{2}{*}{$\begin{array}{l}\text { Esansiyel yağ } \\
\text { hapsetme } \\
\text { etkinliği } \\
\text { Entapment } \\
\text { efficiency (\%) }\end{array}$} & \multirow{2}{*}{$\begin{array}{c}\text { Hausner } \\
\text { Oranı } \\
\text { Hausner } \\
\text { ratio }\end{array}$} \\
\hline & $\begin{array}{c}\text { Arap zamkı } \\
\text { Gam arabic (\%) }\end{array}$ & $\begin{array}{c}\text { Maltodekstrin } \\
\text { Maltodextrin (\%) }\end{array}$ & & & & \\
\hline 1 & 100 & 0 & 39.33 & 81.25 & 84.14 & 1.36 \\
\hline 2 & 50 & 50 & 46.12 & 78.93 & 73.49 & 1.35 \\
\hline 3 & 0 & 100 & na & na & na & na \\
\hline 4 & 25 & 75 & 26.55 & 60.35 & 90.38 & 1.62 \\
\hline 5 & 0 & 100 & na & na & na & na \\
\hline 6 & 100 & 0 & 38.14 & 83.57 & 83.73 & 1.38 \\
\hline 7 & 50 & 50 & 38.22 & 76.61 & 71.49 & 1.25 \\
\hline 8 & 75 & 25 & 29.13 & 67.32 & 71.63 & 1.68 \\
\hline
\end{tabular}

na: uygulanamıyor (\%100 maltodekstrin içerdiği için emülsiyon sağlanamamış ve deney yapılmamıştır).

na: not applicable (emulsion not provided because it contains $\% 100$ maltodextrin so not tested)

Hausner oranı ve Carr indeks mikroenkapsüle haldeki tozların akışkanlığı hakkında bilgi vermektedir. Bu her iki değerinde düşük olması tozların daha akışkan bir yapıda olduğunun bir kanıtıdır ki bu da istenilen bir durumdur. Çünkü bu değerler ürünün paketleme ve taşıma koşulları için önemli bir parametredir. Elde edilen verilere göre en iyi akışkanlığa Mentha spicata esansiyel yağı ile hazırlanmış örnekte ulaşılmasına rağmen tüm örneklerin akışkanlık değerlerinin istenilen düzeyde olmadığı belirlenmiştir. Turchhiuli ve ark. (2005), Fuchs ve ark. (2006), Quispe-Condori ve ark. (2011) tarafından yapılan çalışmada püskürtmeli kurutucu ile mikroenkapsülasyon işleminin uygulandığı yağlarda benzer sonuçlar elde etmişlerdir.

Islanabilirlik, ürünün kompozisyonuna, büyüklüğüne, şekline ve suyun sıcaklı̆ıına bağlı olarak değişmektedir (Tonon, 2006). Elde edilen mikroenkapsüle tozlarda ıslanabilirlik değerleri en düşük 297.5 sn en yüksek 427.5 sn bulunmuştur. Jinapong, (2008) mikroenkapsüle süt tozunda Islanabilirlik değerini 313 sn; Tonon, (2006) maltodekstrinle kaplanmış mikrokapsüle meyve suyunda 380-510 sn bulmuştur. Bu yüzden elde edilen değerlerin literatürde mikroenkapsüle edilmiş diğer yağ örnekleriyle benzerlik gösterdiği belirlenmiştir.

Su aktivitesi, yüzey yağda olduğu gibi mikrokapsüllerin raf ömrünü etkileyen önemli bir parametredir. Toz ürünlerin su aktive değerleri Çizelge 4'te verilmiştir ve Klaypradit, ve Huang, (2008) kuru toz örnekler için belirtmiş olduğu maksimum su aktivitesi değeri $0.3^{\prime}$ dür. Ayrıca mikroenkapsüle haldeki örneklerde belirlenmiş olan su aktivitesi değerlerinin Baranauskiene ve ark. (2013) farklı duvar materyalleri kullanarak mikrokapsüle ettikleri nane esansiyel yağı örneklerinkinden daha düşük olduğu belirlenmiştir. 
Çizelge 4. Mentha spicata ve Mentha piperita mikroenkapsüle esansiyel yağları analiz sonuçları Table 4. Analysis of microencapsulated essential oil of Mentha spicata and Mentha piperita

\begin{tabular}{|l|c|c|c|c|c|c|c|}
\hline $\begin{array}{l}\text { Örnekler* } \\
\text { Samples* }\end{array}$ & $\begin{array}{c}\text { Verim } \\
\text { Yield } \\
(\%)\end{array}$ & $\begin{array}{c}\text { Encapsulation } \\
\text { efficiency } \\
(\%)\end{array}$ & $\begin{array}{c}\text { Esansiyel } \\
\text { yağ } \\
\text { hapsetme } \\
\text { etkinliği } \\
\text { Entapment } \\
\text { efficiency } \\
(\%)\end{array}$ & $\begin{array}{c}\text { Hausner } \\
\text { Oranı } \\
\text { Hausner } \\
\text { ratio }\end{array}$ & $\begin{array}{c}\text { Carr } \\
\text { Indeks } \\
\text { Carr } \\
\text { Index }\end{array}$ & $\begin{array}{c}\text { Islanabilirlik } \\
\text { (sn) } \\
\text { Wettability } \\
\text { (sec) }\end{array}$ & $\begin{array}{c}\text { Su Aktivitesi } \\
\text { Water } \\
\text { Activity }\end{array}$ \\
\hline 1 & $47.2 \pm 0.7$ & $75.9 \pm 3.1$ & $96.85 \pm 0.42$ & $1.36 \pm 0.01$ & $25.6 \pm 0.5$ & $452.5 \pm 10.6$ & $0.144 \pm 0.001$ \\
\hline 2 & $40.1 \pm 1.3$ & $73.7 \pm 5.4$ & $95.97 \pm 0.11$ & $1.28 \pm 0.01$ & $25.6 \pm 2.4$ & $327.5 \pm 3.5$ & $0.156 \pm 0.002$ \\
\hline 3 & $33.1 \pm 0.8$ & $78.9 \pm 7.3$ & $94.45 \pm 0.61$ & $1.57 \pm 0.06$ & $37.1 \pm 0.6$ & $297.5 \pm 17.7$ & $0.196 \pm 0.004$ \\
\hline 4 & $28.5 \pm 1.6$ & $81.1 \pm 4.2$ & $87.48 \pm 0.19$ & $1.75 \pm 0.13$ & $34.8 \pm 1.3$ & $427.5 \pm 10.6$ & $0.215 \pm 0.003$ \\
\hline
\end{tabular}

*1 ve 2 kodlu örnekler $M$. spicata 3, ve 4 kodlu örnekler $M$. piperita mikroenkapsüle esansiyel yağlarını göstermektedir. 1 ve 3 kodlu örnekler arap zamkı-maltodekstrin (\%38-62) kombinasyonu ile 2 ve 4 nolu örnekler \%100 arap zamkı ile üretilmiştir.

* 1,2 and 3,4 represent M.spicata and M. piperita respectively. 1 and 3 were microencapsulated by gam arabic-maltodextrin (38$62 \%$ ) of combination. 2 and 4 were microencapsulated only by gam arabic (100\%)

\section{Sonuçlar}

M.spicata ve M.piperita esansiyel yağlarının mikroenkapsüle edilmesinde kullanılan ancak maliyeti günden güne artan arap zamkı kaplama maddesinin yerine maltodekstrin-arap zamkı (\%62-38) kombinasyonu kullanımı bu teknik için sadece arap zamkı kullanımı kadar etkin olacağı belirlenmiştir. Mikroenkapsülasyon işleminde kaplama maddesi oranı artıkça kaplanan bileşenin daha iyi korunması sağlanmaktadır ancak artan kaplama maddesi miktarı toplam mikrokapsül kütlesi içerisindeki aktif bileşen (kaplanan madde) miktarını azaltıcı etki gösterecektir ki bu da istenmeyen bir durumdur. Duvar materyalinin oranına ve esansiyel yağın elde edildiği nanenin türüne göre verim, etkinlik, esansiyel yağ hapsetme etkinliği, Hausner oranı, Carr indeks, Islanabilirlik (sn) ve su aktivitesi değişkenlik göstermiştir.

Burada alınan veriler nane esansiyel yağı ile sınırlı kalmamalı ve diğer tıbbi ve aromatik bitkilerin esansiyel yağları için benzer araştırmalara tabi tutulmalıdır. Mentha cinsine ait olsalar da her iki nane türünün esansiyel yağlarının biyoaktif özellikleri ve bunların etki mekanizmaları açısından farklılıkları ortaya konmuştur. Benzer çalışmalar diğer tıbbi ve aromatik bitkilerin esansiyel yağları için yürütülmelidir.

\section{Ekler}

Bu çalışmanın tamamı Türkiye Bilimsel ve Teknolojik Araştırma Kurumu tarafından desteklenmiştir. (TUBITAK, Proje No: 1130471).

\section{Kaynaklar}

Aggarwal, K., Khanuja, S., Ahmad, A., Santha Kumar, T., Gupta, V.K., Kumar, S., 2002. Antimicrobial activity profiles of the two enantiomers of limonene and carvone isolated from the oils of Mentha spicata and Anethum sowa. Flavour and Fragrance Journal, 17:59-63.

Baranauskiene, R., Bylaite, E., Zukausaite, J., Venskutonis, R.P., 2007. Flavor retention of peppermint (Mentha piperita L.) essential oil spray-dried in modified starches during encapsulation and storage. Journal of Agricultural and Food Chemistry ,pp. 3027-3036.

Bertolini, A.C., Grosso, C.R.F., 2001. Stability of monoterpenes encapsulated in gum arabic by spray drying. Journal of Agriculture and Food Chemistry, 49:780-785. 
Cai, Y.Z., Corke, H., 2000. Production and Properties of Spray-dried Amaranthus Betacyanin Pigments. Journal of Food Science, 65:1248-1252.

Ciobanu, A., Mallard, I., Landy, D., Brabie, G., Nistor, D., \& Fourmentin, S., 2013. Retention of aroma compounds from Mentha piperita essential oil by cyclodextrins and crosslinked cyclodextrin polymers. Food Chemistry, 138(1): 291297.

Çam, M., Içyer, N. C., Erdoğan, F., 2014. Pomegranate peel phenolics: Microencapsulation, storage stability and potential ingredient for functional food development. LWT - Food Science and Technology, 55(1): 117-123.

Decarvalho, C.C.R., Dafonseca, M.M.R., 2006. Carvone: why and how should one bother to produce this terpene. Food Chemistry, 95:413-422.

Desorby, S.A., Netto, F.M., Labuza, T.P., 1997. Comparasion of Spray-drying, Drum-drying and Freeze-drying for beta carotene Encapsulation and Preservation. Journal of Food Science, 62:1159-1162.

Eichler, K., 2003. Trend in the European Encapsulation Market. Food Marketing and Technology, 17: 42-44.

Fuchs, M., Turchiuri, C., Bohin, M., Cuvelier, M.E., Ordonnaud, and Peypat-Maillard, M.N., 2006. Encapsulation of oil in powder using spray drying and fluidised bed agglomeration. Journal of Food Enginering, 75: 27-35.

Gharsallaoul, A., Roudaut, G., Chambin, O., Voilley, A., 2007. Saurel, R., Applications of spray-drying in microencapsulation of food ingredients: An overview, Food Research International, 40:1107-1121.

Hussain, A.I., Anwar, F., Shahid, M., Ashraf, M., Przybylski, R., 2010. Chemical composition and antioxidant and antimicrobial activities of essential oil of spearmint (Mentha spicata L.) from Pakistan. Journal of Essential Oil Research, 22: 78-84.

Işcan, G., Kirimer, N., Kürkcüoğlu, M., Başer, K. H. C., \& Demirci, F., 2002. Antimicrobial screening of Mentha piperita essential oils. Journal of Agricultural and Food Chemistry, 50(14): 3943-3946.

Jafari, S. M., Assadpoor, E., He, Y., \& Bhandari, B., 2008. Encapsulation efficiency of food flavours and oils during spray drying. Drying Technology, 26(7):816-835. jinapong, N., Suphantharika, M., Jammong, P., 2008. Production of instant soymilk powders by ultrafiltration, spray drying and fluidized bed agglomeration. Journal of Food Engineering, 84:194-205.

Karagözlü, N., Ergönül, B., \& Özcan, D., 2011. Determination of antimicrobial effect of mint and basil essential oils on survival of E. coli $0157: \mathrm{H} 7$ and S. typhimurium in fresh-cut lettuce and purslane. Food Control, 22(12):1851-1855.

Lawrence, B.M., 2006. Mint: The Genus Mentha. CRC Press, Boca Raton, FL.

Lucchesi, M.E., Chemat, F., Smadja, J., 2004.2004. Solvent-free microwave extraction of essential oil from aromatic herbs: comparison with conventional hydrodistillation. Journal of Chromatogrphy, A 1043: 323-327.

Mimica-Dukić, N., Božin, B., Soković, M., Mihajlović, B., \& Matavulj, M., 2003. Antimicrobial and antioxidant activities of three Mentha species essential oils. Planta Medica, 69(5): 413-419.

Moreau, D.L., Rosenberg, M., 1996. Oxidative Stability of Anhydrous Microencapsulated Whey Proteins. Journal of Food Science, 61:39-43.

Oliveira, A.R.M.F., Jezler, C.N.,Oliveira, R.A., Mielke, M.S., Costa, L.C.B., 2012. Determination of hydro-distillation time and harvest time on essential oil of mint. Hortic. Bras, 30:155-159.

Quispe-Condori, S., Saldaña, M. D. A., \& Temelli, F., 2011. Microencapsulation of flax oil with zein using spray and freeze drying. LWT - Food Science and Technology, 44(9):1880-1887.

Ramasubramania Raja, R., 2012. Medicinally potential plants of Labiatae (Lamiaceae) family: An overview, Research Journal of Medicinal Plant, 6(3):203-213.

Sarkar, S., Gupta, S., Variyar, P. S., Sharma, A., \& Singhal, R. S., 2013. Hydrophobic derivatives of guar gum hydrolyzate and gum arabic as matrices for microencapsulation of mint oil. Carbohydrate Polymers, 95(1):177-182.

Şarer, E., Toprak, S.Y., Otlu, B., Durmaz, R., 2011. Composition and antimicrobial activity of the essential oil from Mentha spicata L. subsp. Spicata. Journal of Essential Oil Research, 23:105-108.

Tan, L.H., Chan, L.W., Heng, P.W.S., 2005. Effect of oil loading on microspheres produced 
by spray drying. Journal of Microencapsulation, 22:253-9.

Tatar, F., Tunç, M. T., Dervisoglu, M., Cekmecelioglu, D., \& Kahyaoglu, T., 2014. Evaluation of hemicellulose as a coating material with gum arabic for food microencapsulation. Food Research International, 57:168-175.

Tonon, R.V., 2006. Secagem por atomizaçao do suco de açai: Influencia das variaveis de processo, qualidade e estabilidade do produto. Mater's Thesis. Universidade Estadual de Campinas.

Turchiuli C., Fuchs M., Bohin M., Cuvelier E., Ordonnaud C., Peyrat-Maillard M.N., Dumoulin E., 2005. Oil encapsulation by spray drying and fluidised bed agglomeration. Inn. Food Sci. Emerg. Technol, 6:29-35.

Wojtowicz, E., Zawirska-Wojtasiak, R., Adamiec, J., Wasowicz, E., Przygoński, K., \& Remiszewski, M., 2010. Odor active compounds content in spices and their microencapsulated powders measured by SPME. Journal of Food Science, 75(8): S441-S445.

Younis, Y.M., Beshir, S.M., 2009. Carvone-rich essential oils from Mentha longifolia (L.) Huds. ssp. schimperi Briq. and Mentha spicata L. grown in Sudan. Journal of Essential Oil Research ,16:539-541. 